\title{
Placental Malformation
}

National Cancer Institute

\section{Source}

National Cancer Institute. Placental Malformation. NCI Thesaurus. Code C27050.

A non-neoplastic abnormality that affects the placenta. Representative examples include multi-lobed and bilobed placenta. 